\title{
Targeting Colorectal Cancer Cell Lines Using Nanobodies; AgSK1as a
}

\section{Potential Target}

\author{
Seyed Khalil Rashidi ${ }^{1}$, Seyed Latif Mousavi Gargari ${ }^{1 *}$, Walead Ebrahimizadeh ${ }^{2}$ \\ ${ }^{1}$ Department of Biology, Faculty of Basic Science, Shahed University, Tehran, Iran. \\ ${ }^{2}$ Department of Medical Biotechnology, School of Advanced Medical Sciences and Technologies, Shiraz University of \\ Medical Sciences, Shiraz, Iran. \\ ${ }^{*}$ Corresponding author: Seyed Latif Mousavi Gargari, Department of Biology, Faculty of Basic Science, Shahed University, Opposite of Imam \\ Khomeini’s Shrine, Tehran-Qom, Express Way, 3319118651 Tehran, Iran, Tel: +98 21 51212232, Fax: +98 21 58212201, E-mail: slmousavi@shahed.ac.ir \\ Received: 6 Feb. 2016; Revised: 4 Sept. 2016; $\quad$ Accepted: 19 June 2017; $\quad$ Published online: 19 August 2017
}

Background: Colorectal cancer is the third most common type of aggressive cancers. Chemotherapy, surgery, and radiotherapy are the common therapeutic options for treating this cancer. Due to the adverse side-effects of these methods, immunotherapy is considered as an appropriate alternative therapeutic option. Treatment through the application of monoclonal antibodies is considered as a novel alternative therapeutic method for cancers. The variable fragments of the antibodies' heavy chain or VHHs have a wide application in molecular biology and biotechnology. VHHs are compatible with the phage display technology which allows rapid and high throughput screening for antibodies isolation.

Objectives: We aimed to use naive VHH phage library to isolate a specific nanobody against colorectal tumor associated antigen; the AgSK1.

Materials and Methods: In this research, naive VHH phage library was panned against two colorectal cell lines; Ls174T and HT29 expressing different levels of AgSK1 tumor associated marker. The high affinity binders were selected and subcloned for higher expression levels of the VHH. The affinity and specificity of the isolated VHH were tested using ELISA. The reactivity of the VHH toward cancer cells was analyzed by competitive ELISA applying sera isolated from colorectal cancer patients.

Results: Results show that the isolated VHH recognizes and binds to the colorectal cancer cells with a high affinity. Moreover, the isolated nanobody is able to compete with the antibodies in the patient sera for the binding to the cancer cells.

Conclusions: Results suggest that this nanobody has a specific reaction toward colorectal cells and can be used for further investigation on the tumor associated antigens or production of mimotopes useful for immunotherapy.

Keywords: AgSk1, Cell-panning, Colorectal Cancer, VHH nanobody

\section{Background}

Colorectal cancer is the third cause of death after prostate and lung cancers among men and the second after breast cancer among women (1). The annual death rate caused by colorectal cancer is more than 50,000 . In addition, more than 120,000 new cases are diagnosed each year. The incidence of colorectal cancer is much higher for the age range above 50 (2).

Early diagnosis of colorectal cancer has a significant impact on the disease's treatment in the initial stages (3). 40 to $50 \%$ of colorectal cancer cases will develop metastasis in the course of the disease (4), and the average lifetime of patients after diagnosis with metastatic cancer is less than 5 years, therefore, early diagnosis and treatment reduces the risk of metastasis (5). In most cancers, the available treatments are used to mitigate the pain and control of symptoms, thus are not considered as curative (6).

Chemotherapy is considered as a common treatment method for most cancers, however, the side-effects associated with the therapeutic agent prevent the effective dose usage for eradicating cancer. Also, 
using low dosage often results in the development of resistance to the chemotherapeutic agent (7).

As an alternative method, treatment with monoclonal antibodies has greater advantages compared to the chemo- or radiotherapy (8). Cancer cells have different expression patterns and development of antibodies recognizing these differences can specifically target cancer cells (9). Due to the specificity of monoclonal antibodies in recognition of their target, they can be employed to deliver chemotherapeutic drugs to the cancer calls or be modified to develop immunotoxins that specifically target cancer cells (10).

Factors associated with the appropriateness of the antibodies in the cancer therapy are: the high affinity towards tumor associated antigen, homology with human proteins, the absence of protease sensitive domains, high solubility, and stability (11). Antibody fragments such as $\mathrm{Fab}$ and $\mathrm{ScFv}$ can also interact with the antigens. These fragments have a number of advantages over the whole antibodies, such as, a higher tissue penetration, a property useful against solid tumors, higher serum clearance which is helpful in case of immunotoxins and radiolabel fragments, plus lower immunogenicity which increases its halflife and reduces the needed dosage (12). Nevertheless, the high expense associated with the development of these antibodies and the need for eukaryotic expression system limit their use (13).

Antibody fragments bear most of the advantages attributed to the monoclonal antibodies and antibodies. VHHs (variable fragments of heavy chain antibodies) or nanobodies are fragments of the naturally developing single chain antibodies of camelid species and sharks (14). These antibodies lack the light chain of conventional antibodies and possess antigen binding capability. Due to lack of light chains in the antibody binding fragments of these single chain antibodies, the VHH size is reduced to less than $15 \mathrm{KDa}$ along with a high solubility potential. These properties provide $\mathrm{VHH}$ with high tissue diffusion rate necessary for treatment of the solid tumors $(15,16)$. Further advantages of the VHHs are the simplicity of expression in prokaryotes and other microorganisms, high homology with human $\operatorname{IgG}$ antibodies, and compatibility with the high throughput selection systems such as phage-, yeast- and ribosome-display (17). Furthermore, VHHs have extended CDR3 region that enables these fragments to recognize the hidden epitopes such as enzyme active sites and haptens, as well (18).

Isolated from lymphocytes of the colorectal patients, SK1 monoclonal antibody specifically recognizes and binds to the AgSK1 surface protein. Immunohistochemistry and dot-blot have revealed that this antibody can react with several colorectal cancer cell lines, while it is does not bind to the normal cells such as fibroblasts, lung cell lines, blood cells, and other cells derived from normal tissues. These features show the specificity of this antibody toward colorectal cancer tissues (19).

Colorectal cancer derived cell lines show different expression levels of AgSK1; the highest expression level of which belongs to the SW620 and Ls174T cell lines, and the lowest expression levels were seen for $\mathrm{CaCO}_{2}$ and HT29 cell lines. A higher expression level of AgSK1 is associated with a higher likelihood for metastasis development (20).

\section{Objectives}

Because the AgSK1 protein is still an unknown antigen, in this research we aimed to isolate a VHH nanobody that could specifically recognize and bind to the cell line that expresses AgSK1 tumor associated antigen. We then compared the reactivity of the isolated $\mathrm{VHH}$ with the control cell lines and sera of the colorectal patients.

\section{Materials and Methods}

\subsection{Bacteria and Cell Lines}

E. coli BL21(DE3) and E. coli TG1 were obtained from Shahed University bacterial collection and were cultured in Luria-Bertani (LB) medium ( $1 \% \mathrm{NaCl}, 1 \%$ Peptone, and $0.5 \%$ yeast extract).

HT29, Ls174T, and HeLa cell lines were purchased from Pasture Institute of Iran (Tehran, Iran) and were cultured in the DMEM (Dulbecco's Modified Eagle's Medium) medium containing $10 \%$ FBS at $37^{\circ} \mathrm{C}$ and $5 \%$ $\mathrm{CO}_{2}$.

\subsection{Preparation of the VHH Phage Library}

The naive VHH phage library was from our previous studies (18). Briefly, peripheral blood lymphocytes were isolated from a Camelus dromedarius and used for total RNA extraction, cDNA was generated, and VHH genes were amplified using nested PCR. The library was created by cloning all the VHH genes into pComb3X phagemid vector. After transformation of $E$. coli TG1 bacteria with the library the phage particles harboring the $\mathrm{VHH}$ gene were propagated by infecting the bacteria with the helper phage (M13K07, Amersham, USA), as explained before (18). VHH coding phage particles were isolated from supernatant following to the removal of bacteria by centrifugation and were used for bio-panning. 


\subsection{Biopanning Against Colorectal Cell Lines}

LS147T cell line which expresses high levels of the AgSK1 protein was used for the selection of VHH nanobodies, whereas HeLa cell line lacking AgSK1 was used in a counter-selection step to remove nonspecific VHH nanobodies.

Briefly, cells were cultured in the complete DMEM medium (10\% FBS 2 mM L-glutamine, 100 unit. $\mathrm{mL}^{-1}$ penicillin and $100 \mu \mathrm{g} \cdot \mathrm{mL}^{-1}$ Streptomycin) at $37{ }^{\circ} \mathrm{C}$ supplied with $5 \% \mathrm{CO}_{2}$ for 24 hours. A total number of $5 \times 10^{4}$ cells from each cell line were counted and transferred into separate $1.5 \mathrm{~mL}$ microtubes containing $1 \mathrm{~mL}$ complete DMEM medium and incubated for 2 hours. Cells were sedimented at $1200 \times g$ and washed twice with $0.5 \mathrm{~mL}$ of cold PBS. The total amount of $150 \mu \mathrm{L}$ of the phage library was added to the microtube containing HeLa cell line and was incubated for 2 hours. After centrifugation at $1200 \times g$ at $4{ }^{\circ} \mathrm{C}$ for 5 minutes, the supernatant containing unbound phages was removed and added to the microtube containing Ls 174 T cell line. After 2 hours of incubation, cells were centrifuged as before, washed three times with cold PBS, followed by three times of washing with PBS-T (PBS $+0.05 \%$ Tween-20). The supernatant was removed and the bound phages were eluted by addition of 100 $\mu \mathrm{L}$ Glycine- $\mathrm{HCl}$ solution $(2 \mathrm{M} \mathrm{HCl}, \mathrm{pH}$ was adjusted to 2.2 with Glycine). After 10 minutes of incubation, the eluted phages were harvested by centrifugation and were neutralized to $\mathrm{pH} 7.2$ by the addition of $1 \mathrm{M}$ Tris buffer, $\mathrm{pH}$ 9. The eluted phages were used to infect $E$. coli TG1 at mid-log phase.

The phage particles were propagated as described before (21) and were used for the subsequent panning rounds. A total of four rounds of biopanning were performed. To isolate the highest affinity binders, the concentration of Tween-20 in the washing solution was gradually increased to reach $0.3 \%$ in the final round of panning.

\subsection{Selection of VHH Clones}

Polyclonal phage ELISA was performed to select the highest affinity VHH nanobodies from each round of panning. A total number of $5 \times 10^{4}$ from each of Ls174T, HT29, and HeLa cell lines were cultured in the separate wells of the microplate with $200 \mu \mathrm{L}$ complete DMED medium and cultured for 24 hours at $37^{\circ} \mathrm{C}$ supplemented with the $5 \% \mathrm{CO}_{2}$. The medium was removed and cells were washed with $200 \mu \mathrm{L}$ of cold PBS. $100 \mu \mathrm{L}$ of the eluted phages, which equals to $3 \times 10^{10}$ of the phage particles from each round of panning was added to each well. The plate was incubated for 1 hour at $37^{\circ} \mathrm{C}$. The cells were washed three times with $200 \mu \mathrm{L}$ of PBS and subsequently three times of $200 \mu \mathrm{L}$ PBS-T $(0.05 \%$ Tween-20). $100 \mu \mathrm{L}$ of anti-M13 antibody conjugated with HRP (Diluted to 1:9000 with PBS) (Amersham, USA) was added to each well and the plate was incubated for 30 minutes at $37{ }^{\circ} \mathrm{C}$. The supernatant was removed and cells were washed three times with PBS-T. Subsequently, $100 \mu \mathrm{L}$ of TMB solution was added to each well and the plate was incubated for 15 minutes. The reaction was stopped by addition of 100 $\mu \mathrm{L} 3 \mathrm{~N} \mathrm{H}_{2} \mathrm{SO}_{4}$. The OD was read at $450 \mathrm{~nm}$.

$\mathrm{VHH}$ clones showing the highest absorbance were selected. A total number of 20 clones were selected and analyzed for binding activity as described above.

\subsection{Soluble Expression of VHH Nanobodies}

The clone with the highest absorbance was selected for soluble expression. The VHH gene was cloned into pET28a expression vector. The VHH gene was amplified using primers; Fr4-EcoRI and Fr1-HindIII (18) and then was cloned into pET28a vector using EcoRI and HindIII restriction digestion and subsequent cloning. The construct was transferred into $E$. coli BL21(DE3). The expression was induced with1 $\mathrm{mM}$ IPTG (isopropyl $\beta$-D-1-thiogalactopyranoside) at mid-log phase. Cells were collected six hours after induction by centrifugation and re-suspended in lysis buffer $\left(100 \mathrm{mM} \mathrm{NaH}_{2} \mathrm{PO}_{4}, 10\right.$ $\mathrm{mM}$ Tris base, $8 \mathrm{M}$ urea, $\mathrm{pH} 8$ ). The cells were lysed by sonication and incubated at $37^{\circ} \mathrm{C}$ for 18 hours to dissolve inclusion bodies. Cell debris was removed by centrifugation at $12000 \times \mathrm{g}$ for 15 minutes and the protein content was analyzed by $12 \%$ SDS-PAGE.

VHH nanobody was purified using Ni-NTA affinity chromatography and confirmed by western blotting. The VHH nanobody was refolded by dialysis against descending concentration of urea in PBS. Protein concentration was determined by Bradford method.

\subsection{Affinity Analysis Against Colorectal Cell Lines} Ls174T, HT29, and HeLa cell lines, each at the concentration of $5 \times 10^{4}$ were used for affinity determination. For each cell line, four concentrations of nanobody were tested. Cells were transferred into $1.5 \mathrm{~mL}$ microtubes and nanobody at the concentrations of $0,1,3$, and $6 \mu \mathrm{g}$ in $100 \mu \mathrm{L}$ of PBS was added to each test tube separately. The tubes were incubated for 2 hours and then washed 6 times using PBS-T $(0.05 \%$ Tween-20). Anti-His tag antibody (Amersham, USA) was added and the tubes were incubated for 30 minutes at $37{ }^{\circ} \mathrm{C}$. After washing the cells, $100 \mu \mathrm{L}$ of TMB solution was added and tubes were incubated for 15 minutes. The reaction was stopped using $100 \mu \mathrm{L}$ of $3 \mathrm{~N}$ $\mathrm{H}_{2} \mathrm{SO}_{4}$ and the absorbance was read at $450 \mathrm{~nm}$. 


\subsection{Analysis of VHH Target by Western Blotting}

For analysis of the target recognized by the VHH, $10^{6}$ cells from each of the Ls174T, HT29, and HeLa cell lines were suspended in $200 \mu \mathrm{L}$ of lysis buffer $(100 \mathrm{mM}$ Tris-HCl, pH $8.0-100 \mathrm{mM} \mathrm{NaCl}-0.5 \%$ (v/v) Triton $\mathrm{X}-100)$ separately and were incubated at $4^{\circ} \mathrm{C}$ for 15 minutes. Cell debris was removed by centrifugation at $1200 \times g$ at $4{ }^{\circ} \mathrm{C}$ for 5 minutes. The supernatant was loaded into the wells of $12 \%$ SDS-PAGE and subsequently the electrophoresed proteins were transferred onto the nitrocellulose membrane using western blot system (BioRad). The nitrocellulose membrane was incubated in the blocking solution containing 5\% skim milk and PBS for 18 hours at $4{ }^{\circ} \mathrm{C}$. Following to washing the membrane, nanobody solution at the concentration of $300 \mu \mathrm{g} \cdot \mathrm{mL}^{-1}$ was added, and the membrane was incubated at $37{ }^{\circ} \mathrm{C}$ for 2 hours. The membrane was washed with PBS-T (0.05\% Tween-20) and anti histag antibody was added. The membrane was washed and after 1 hour and $\mathrm{DAB}$ (diaminobenzidine) solution (30 mM tris- $\mathrm{HCl} \mathrm{pH} 7.2,0.6 \mathrm{mg} \cdot \mathrm{mL}^{-1} \mathrm{DAB}$, and 10 $\mu \mathrm{L} \cdot \mathrm{mL}^{-1} \mathrm{H}_{2} \mathrm{O}_{2}$ ) was added. The reaction was stopped by addition of PBS.

\subsection{Analysis of the Binding Activity by Competitive ELISA}

In order to test the reactivity of isolated $\mathrm{VHH}$, a competitive ELISA was designed using colorectal cancer cell lines and sera of patients suffering colorectal cancer. Blood samples were obtained from Cancer Research Institute, Imam Khomeini hospital, Tehran, Iran. Blood samples of healthy individuals were used as negative control.

A total number of $5 \times 10^{4}$ cells from each of Ls174T, HT29, and HeLa cell lines were separately transferred into $1.5 \mathrm{~mL}$ microtube. $100 \mu \mathrm{L}$ of 1:25 diluted sera and $100 \mu \mathrm{L}$ of $\mathrm{VHH}$ nanobody $(6 \mu \mathrm{g})$ were added to each tube. Two control reactions, one without VHH nanobody and the other with sera of the healthy individuals were conducted, as well. After 2 hours of incubation at $37^{\circ} \mathrm{C}$, cells were washed three times with PBS and then anti-His tag antibody was added to each of microtube. The assay was continued as described in the section of "Affinity analysis against Colorectal Cell Lines."

In a different reaction $200 \mu \mathrm{L}$ of sera was added to the same number of cells and cells were washed after 2 hours of incubation and $200 \mu \mathrm{L}$ of VHH nanobody was added. The concentrations of the sera and VHH were the same as the first reaction. The assay was continued as above.

\section{Results}

\subsection{Bio-panning}

The generated VHH-Phage library was confirmed by PCR using specific VHH primers on random colonies isolated from the library (Fig. 1-A). PCR was performed on the phages isolated from each panning round to
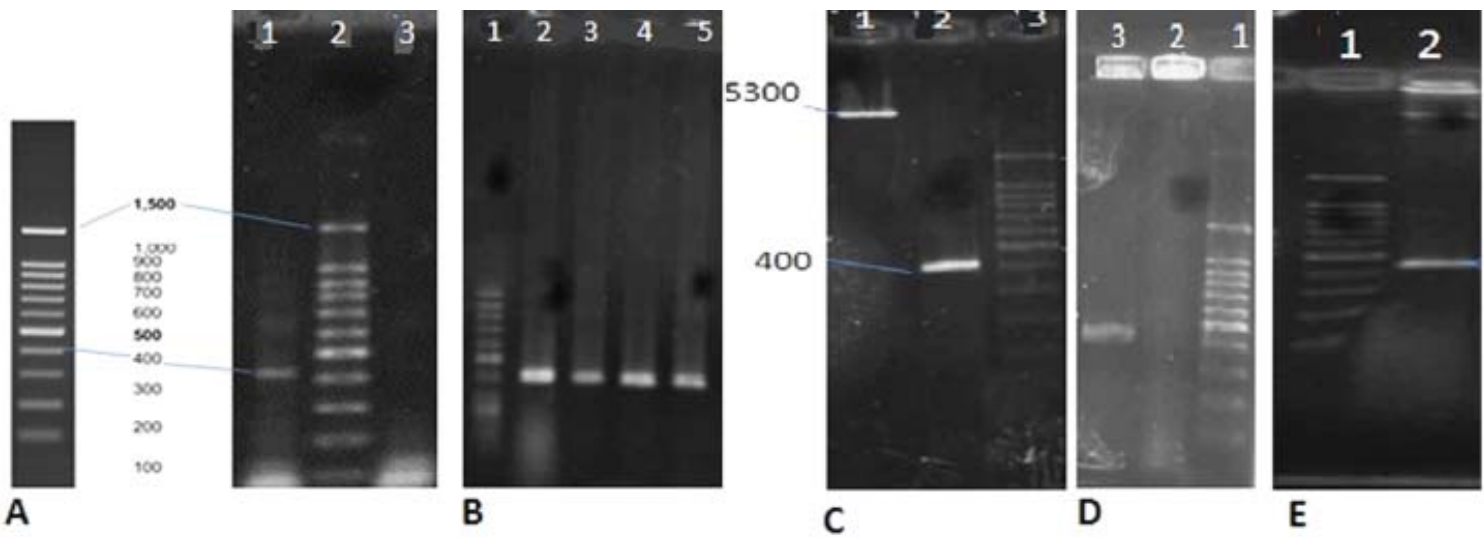

Figure 1. A) Colony PCR on the naive library. Lane 1; 400 bp band represents nanobody gene. Lane 2; Standard DNA molecular weight marker. Lane 3; Negative control. B) Colony PCR on bacteria infected with the phages obtained from panning rounds. Lane 1; Standard DNA molecular weight marker. Lanes 2 to 5; Panning rounds 1 to 4 respectively. C); Lane 1; Digestion of pET28a with EcoRI and HindIII, Lane 2; Digested PCR product of the nanobody using EcoRI and HindIII restriction enzymes. D) Lane 3; PCR using specific nanobody primers on the pET28a clone bearing the VHH gene. The $400 \mathrm{bp}$ band confirms the cloning the VHH gene into the pET28a vector. Lane 2; PCR using specific nanobody primer on the pET28a vector. As seen in the figure no bands can be seen. E) Restriction digestion of the pET28a vector bearing the nanobody gene. Digestion was done using EcoRI and HindIII enzymes flanking the nanobody gene. As shown in the figure the 400 bp band represents the nanobody gene. 
Polyclonal Phage ELISA

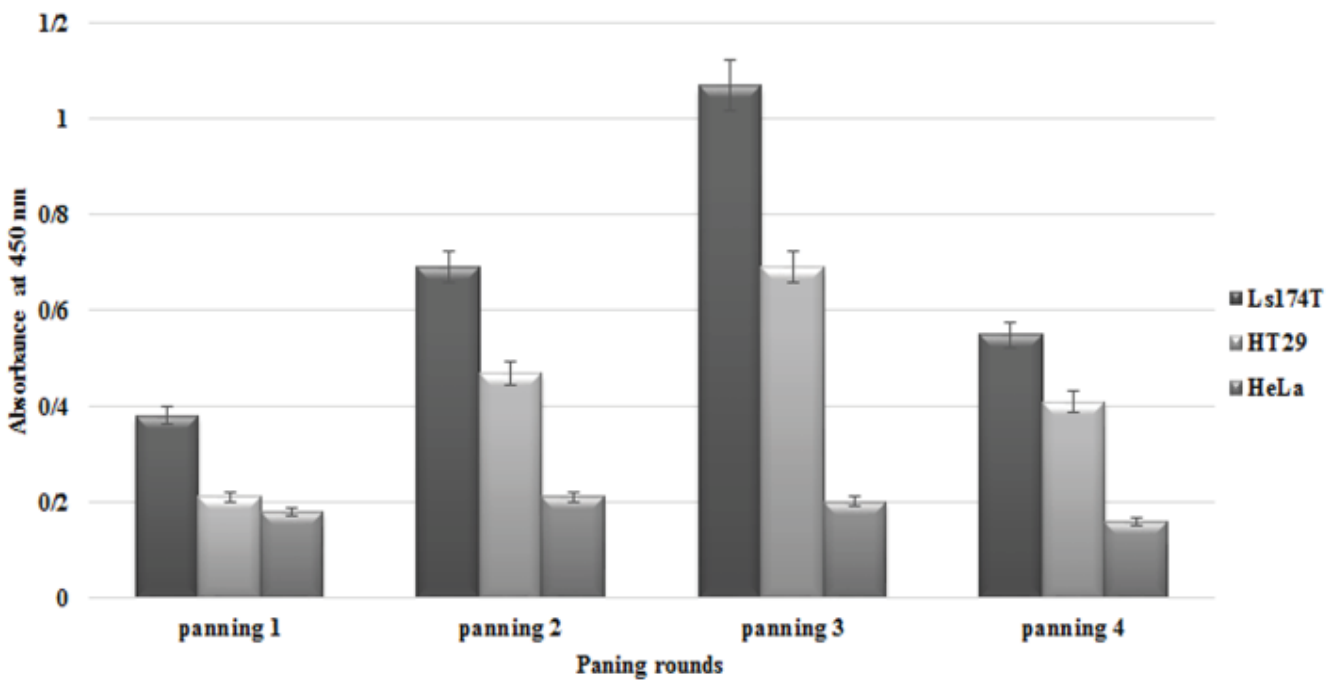

Figure 2. The polyclonal phage ELISA from all the four panning rounds. The third round of panning which showed the highest absorbance was chosen for further isolation of the monoclonal nanobody.

confirm selection of VHH coding phage particles (Fig. 1-B). Cloning of the nanobody in the pET28a was confirmed using PCR on the construct (Fig. 1-D) and by digestion using EcoRI and HindIII enzymes. (Fig. $1-\mathrm{E})$.

Progression of biopanning rounds was monitored using polyclonal phage ELISA on Ls174t, HT29, and HeLa cell lines (Fig. 2). The third round showed the highest absorbance and was selected for further selection of VHH clones.
Twenty clones were selected from the third round of panning and were analyzed for the binding activity toward Ls174t, HT29, and HeLa cell lines. The clone number 4 that was expressing the highest amount of AgSK1, showed the highest affinity toward Ls174t cell line (Fig. 3). This clone was selected for subcloning and expressing the nanobody in a soluble condition.

\subsection{Expression of VHH Nanobody}

The clone number 4 which showed the highest affinity

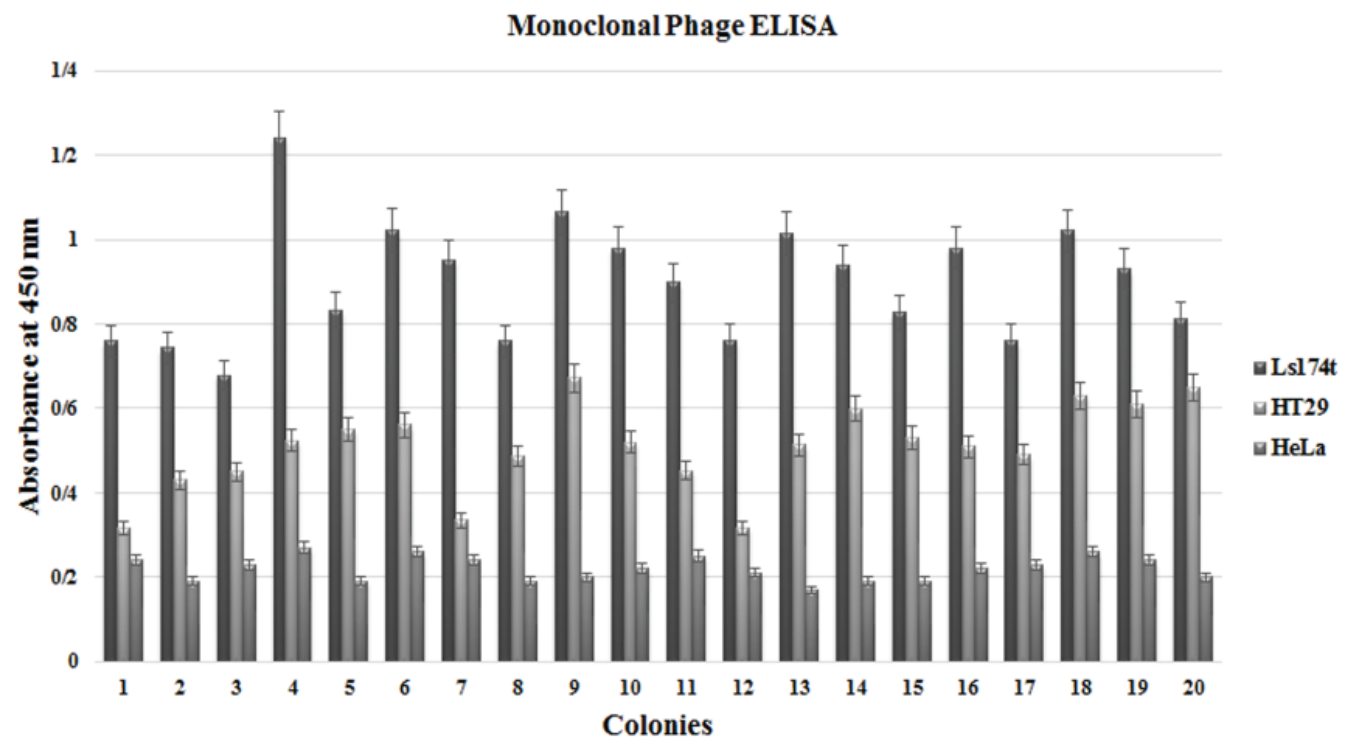

Figure 3. The ELISA results of the monoclonal phage panning. Random colonies were isolated from the third round of panning and were tested for binding strength toward the AgSK1 ${ }^{+}$cell lines. Clone 4 had the highest absorbance and was chosen for soluble expression of the nanobody. 


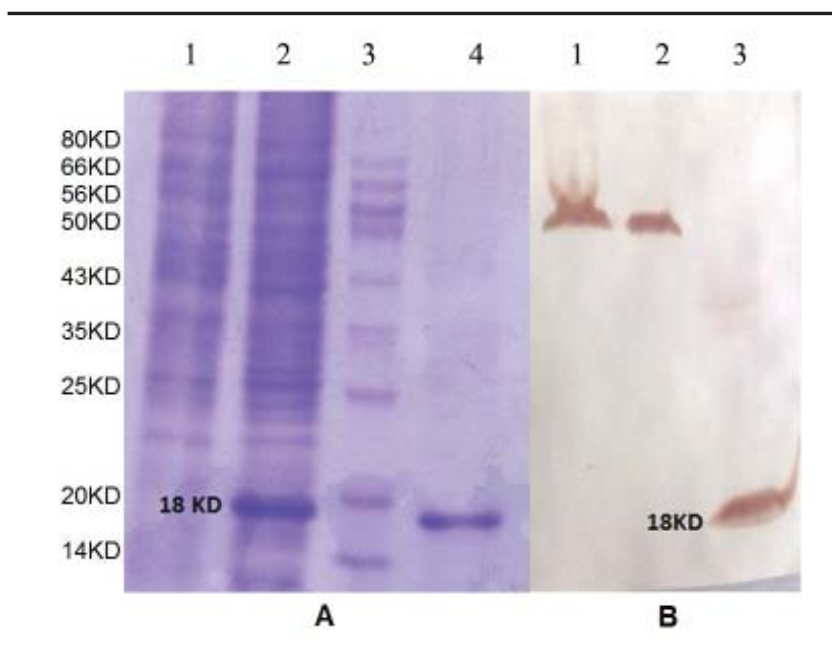

Figure 4. A) Respectively from right to left. Expression of nanobody in soluble form. Lane 1: un-induced negative control. Lane 2: Induced sample. Lane 3: Standard protein molecular marker. Lane 4: The purified nanobody using IMAC column. B) Western blot. Isolated nanobody was used as a primary antibody and anti His-tag antibody was used as secondary antibody. Extracts obtained from different cell types lines were loaded in different wells. Respectively from left to right. Lane 1: Cell extract of LS174T cell line. Lines 2: Cell extract of HT29 cell line. Line 3: Nanobody was loaded as a positive control.

toward Ls174t cell line was subcloned into pET28a in order to express in the E. coli. The gene was amplified using $\mathrm{VHH}$ subcloning primers and then cloned into the EcoRI and HindIII restriction sites of the pET28a vector. Cloning was confirmed by PCR (Fig. 1-C).
The expression of VHH was induced using $1 \mathrm{mM}$ IPTG and the VHH nanobody was purified using NiNTA affinity chromatography. Figures 4A and 4B show the results of SDS-PAGE and Western blot analysis, respectively.

\subsection{Analysis of Binding Activity of the VHH Nanobody}

The binding activity of the VHH nanobody was tested using Ls174t, HT29, and HeLa cell lines. At $6 \mu \mathrm{g} .100$ $\mu \mathrm{L}^{-1}$ concentration, the highest binding activity was seen toward Ls174t cell line and followed by the HT29 cell line. Binding toward HeLa cell line was not significant (Fig. 5). 4.4. Western Blot on Cell Lines Using Isolated Nanobody For recognizing the target for the isolated VHH, Western blot was carried out on the cell lysate of all cell lines. The target was found to be a protein with the molecular weight of $50 \mathrm{KDa}$ on Ls174t and HT29 cell lines (Fig. 4-B).

\subsection{Competitive ELISA}

The competitive ELISA was used to ensure that the target for $\mathrm{VHH}$ nanobody is a tumor-associated antigen that induces the immune system of the patients with colorectal cancer. Sera isolated from patients and healthy individuals were used in a competitive ELISA with the VHH nanobody. The obtained results showed that unlike sera of the healthy individuals, the sera of the cancer patients contain antibodies capable of competing with the VHH nanobody for binding to the colorectal cancer cell lines, however the recombinant nanobody showed a higher binding capacity than the sera of patients (Fig. 6).

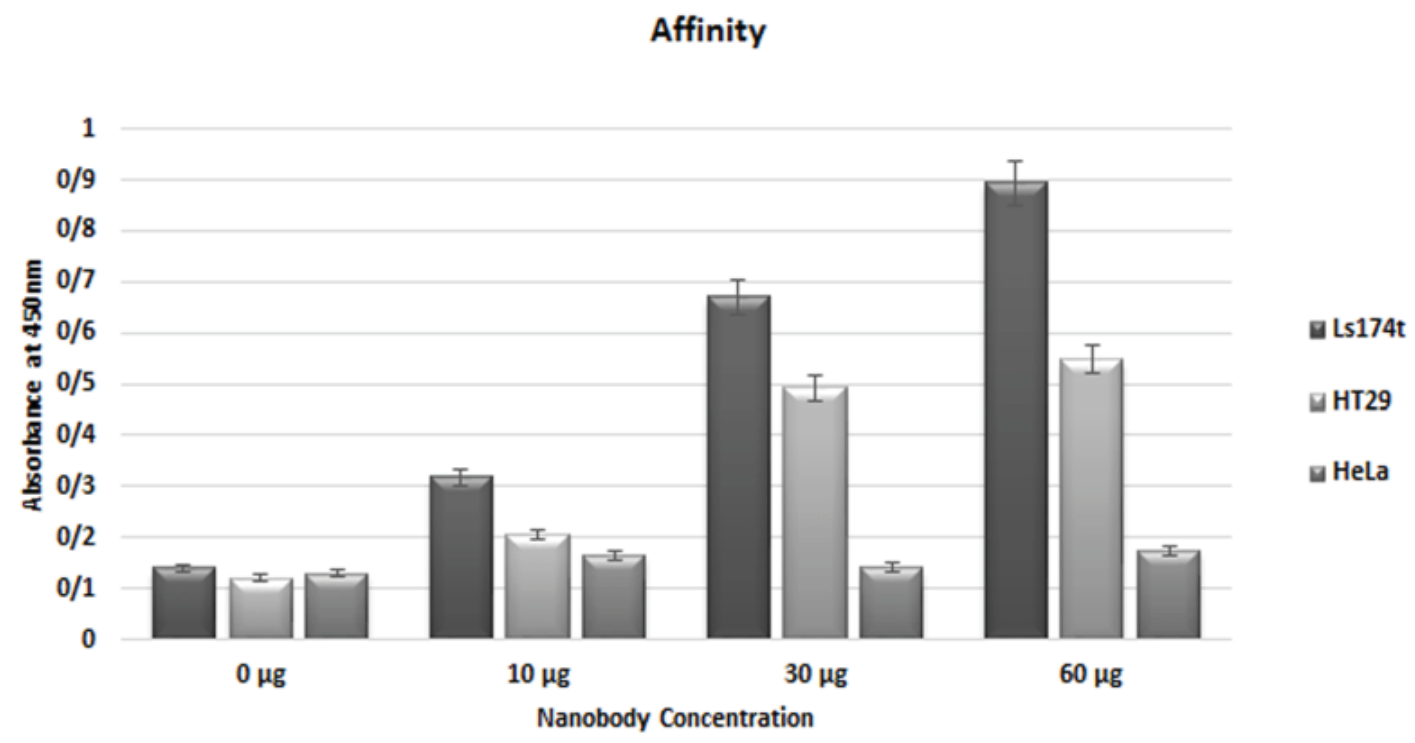

Figure 5. The binding activity assessment of the isolated nanobody at different concentration. LS174T, HT29, and HeLa cell lines were used as the target. As seen LS174T with highest AgSk1 expression shows the highest absorbance. 

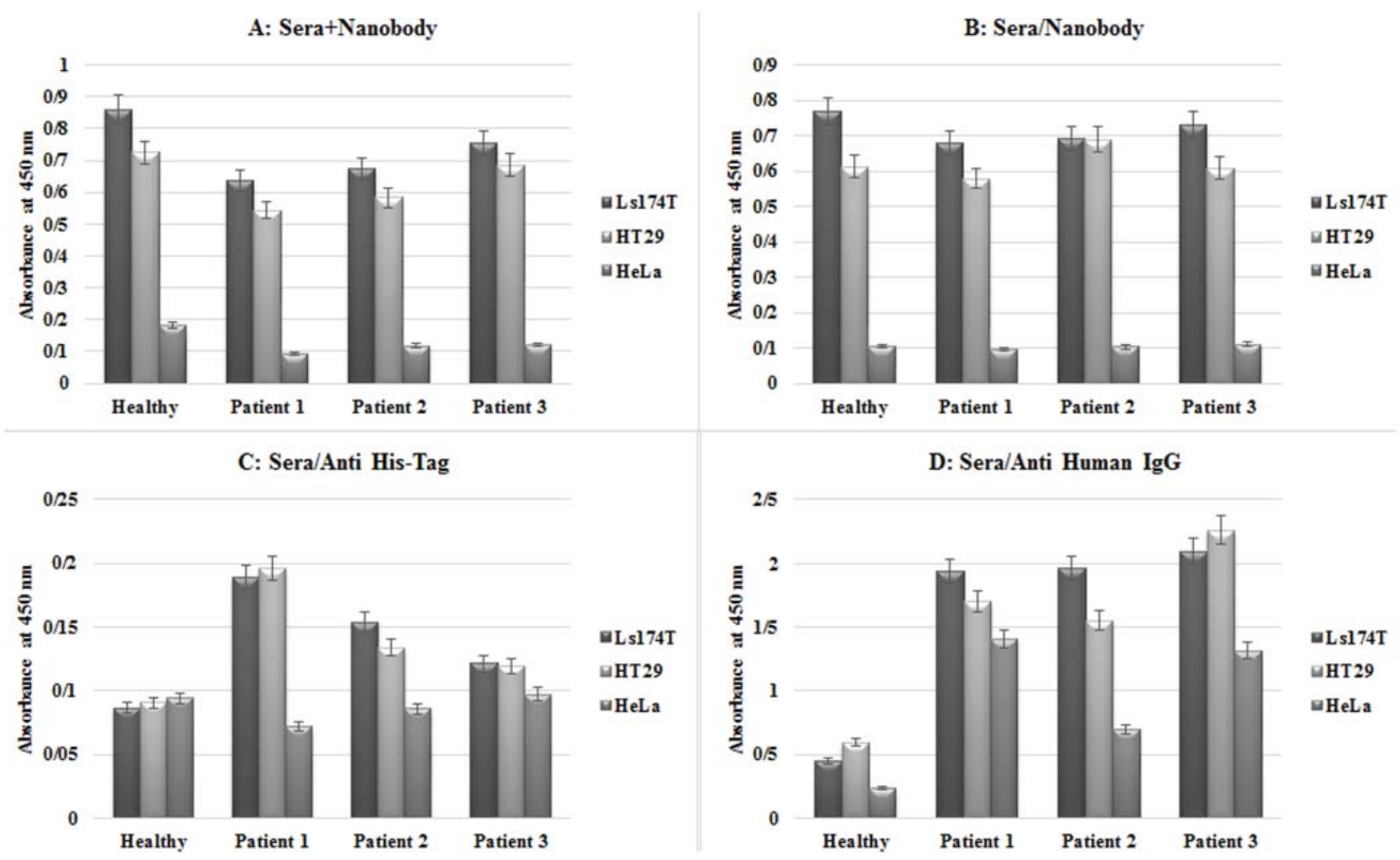

Figure 6. The competitive ELISA assessment on the binding activity of the isolated nanobody in the presence of the antibodies present in the sera of the patients suffering from colorectal cancer. All cells were used at the concentration of $10^{4}$ cells per reaction. A) The control sera or sera from the patients at a dilution of 1:25 were prepared through mixing with PBS and then combined with a volume of $100 \mu \mathrm{L}$ of the nanobody at a concentration of $60 \mu \mathrm{g} \cdot \mathrm{mL}^{-1}$ and subsequently were added to each cell line in a separate reaction. Cells were washed with PBS after $1 \mathrm{~h}$ incubation at $37^{\circ} \mathrm{C}$ anti His- tag antibody was used as the secondary antibody. B) The control sera or sera from patients were used at the dilution of 1:25 in $100 \mu \mathrm{L}$ of PBS was added to each cell line in the separate reactions. After $1 \mathrm{~h}$ of incubation at $37^{\circ} \mathrm{C}$, cells were washed with PBS and then $100 \mu \mathrm{L}$ of nanobody at $60 \mu \mathrm{g} \cdot \mathrm{mL}^{-1}$ was added. After $1 \mathrm{~h}$ incubation at $37^{\circ} \mathrm{C}$, cells were washed with PBS and the assay was carried out as before. Anti His-tag antibody was used as the secondary antibody. C) ELISA was carried out only with control or patients sera. Anti His-tag antibody was used as the secondary antibody. D) ELISA was carried out only on control or patients sera. Anti-human IgG antibody was used as the secondary antibody.

\section{Discussion}

With an average life-expectancy of less than five years, colorectal cancer among the most common types of cancer in the world. It ranks the fourth in men and the third among women. It is also the third cause of cancer related mortality among both sexes (1).

The common treatment methods such as chemotherapy, surgery, and radiotherapy have found to be accompanied with a number of disadvantages. As well, among the other major problems associated with the common treatment methods are the late diagnosis and lack of specificity of the treating agents which affects the normal tissue and causes major tissue damage (2).

Lack of specificity in the current treatment strategies signifies the need for new diagnosis and treatment methods with higher specificity. The use of antibodies in diagnosis and therapy provide specificity and efficiency with the reduced side-effects compared to the common chemotherapy methods.

Various antibodies have been developed for the treatment of colorectal cancer (22-25). Several drawbacks are associated with the chimeric mousehuman antibodies such as high cost of production and the possibility of viral contamination, thereby limit their production and application. Another problem related to the development of antibodies by hybridoma technology is the HAMA (human anti-mouse antibody) response. The mouse domains of chimeric antibodies can induce an immunological response which results in the production of neutralizing antibodies, therefore, reduction of the effective dose with the possible sideeffects.

Unlike hybridoma technology, phage display is fast and can be customized to obtain antibodies with the desired characteristics. The production of antibody 
without immunization steps and ease of genetic manipulations are among the other advantages of the phage display over hybridoma technology.

Among antibody fragments, VHHs are more stable, and can easily be produced in microorganism in large scales (17). These antibody fragments are resistance to the temperature and proteolytic digestion by proteases, thus having longer shelf life and can be administrated orally (26). Lack of FC fragments in these antibodies reduces non-specific interactions (27). Currently, there are not too many specific tumor markers for the colorectal cancer. The introduction of AgSK1 as a specific tumor marker presents an opportunity for an early diagnosis and specific treatment of colorectal cancer, as well. Recent studies on this antigen have shown that antibodies against AgSK1 react with 11 colorectal cancer cell lines without showing reactivity toward normal cell lines such as the fibroblast (28). Also, these antibodies haven't shown any cross reaction with the other antigens such as CEA, CA19-9, and TAG72 (28).

Based on these information we aimed to isolate a VHH nanobody against the cell line that expresses the highest level of AgSK1. The reason for performing cell-based panning was the fact that AgSK1 gene still remains unknown. Furthermore, cDNA sequences obtained from the previous literature didn't result in protein expression. Additionally, cell panning enables isolation of antibodies against the native cell surface proteins with a correct folding hence exhibiting more in vivo specific reactivity.

Williams et al. have immunized BALB/c mice using the colorectal cancer cell lines (SW480, SW948, and SW837)(29). ScFv library was prepared from the Fab fragments of the mice antibodies and was panned against SW480 and SW837 cell lines along with Ovalbumin (OVA) as a negative control. Antibodies isolated by cell panning have shown a high affinity toward the cells. The SW480 and SW837 cell lines showed an OD 2.5 fold higher than the negative control in the cell ELISA test. Although we didn't obtain a 2.5 fold difference in the absorbance between the test and control reactions, but, we have used cell lines in the both test and control reactions, thereby we have eliminated the possibility of false-positive results and providing a condition resembling the in vivo setting. In addition, the naive library used in our research usually results in the antibodies with the less affinity compared to the immune libraries.

A similar study was conducted by Zhou et al. where the human scFv library was used for isolation of the antibody fragments against EGFR expressed in a prokaryotic system. The isolated antibodies were evaluated by ELISA using cell lines over-expressing EGFR (30). In addition, A431 cell line and skim milk were used as negative controls in the two different reactions. The $\mathrm{scFv}$ antibody against endothelial growth factor receptor 2 was used to evaluate nonspecific binding. The absorbance for test reaction was 0.55 and that of the negative control was 0.05 . The absorbance of cell lines alone was 0.2 which shows the false-positive results when the fixed cells are used for ELISA. The naive library was used in this study describes the low affinity of the isolated antibody. In our study, the absorbance of test reaction was 0.9 and that of the negative control was 0.18 , slightly better than the results of Zhou et al.

The reactivity of the isolated VHH nanobody with its potential target was tested by western blot analysis on cell lysates obtained from colorectal cell lines. The nanobody had a specific reaction against Ls174t and HT29 cell lines, but, no reactivity toward the HeLa cell lysate. The specificity of the nanobody was also tested by using competitive ELISA through application of sera obtained from patients suffering from colorectal cancer. Patients whom underwent chemotherapy or radiotherapy were excluded from the analysis due to the potential weakness of the immune system during these treatments. Unlike the sera of the healthy individuals, sera of the patients could compete with the isolated nanobody for binding to the cell surface antigens of the colorectal cancer cell lines. This reactivity was not seen for the other cell lines such as HeLa. This indicates that isolated nanobody can target a tumor associated antigen specific to the colorectal cells.

Although further research is needed to fully identify the binding target for this nanobody, however, our findings suggest that this nanobody has a specific reaction toward colorectal cells and can be used for further investigation on the tumor associated antigens or production of mimotopes useful for immunotherapy.

\section{Acknowledgment}

The authors wish to thank Shahed University and Biotechnology Development Council of I.R. Iran for their financial support.

\section{References}

1. Ferlay J, Shin HR, Bray F, Forman D, Mathers C, Parkin DM. Estimates of worldwide burden of cancer in 2008: GLOBOCAN 2008. Int J Cancer. 2010;127(12):2893-917. DOI: 10.1002/ ijc. 25516

2. Barderas R, Babel I, Díaz-Uriarte R, Moreno V, Suárez A, Bonilla $\mathrm{F}$, et al. An optimized predictor panel for colorectal cancer 
diagnosis based on the combination of tumor-associated antigens obtained from protein and phage microarrays. J Proteom. 2012;75(15):4647-55. DOI:10.1016/j.jprot.2012.03.004

3. Sanoff HK, Sargent DJ, Campbell ME, Morton RF, Fuchs CS, Ramanathan RK, et al. Five-year data and prognostic factor analysis of oxaliplatin and irinotecan combinations for advanced colorectal cancer: N9741. J Clin Oncol. 2008;26(35):5721-7. DOI: $10.1200 /$ JCO.2008.17.7147

4. Field K, Lipton L. Metastatic colorectal cancer-past, progress and future. World J Gastroenterol. 2007;13(28):3806. DOI: 10.3748/wjg.v13.i28.3806

5. Mitchell EP. Targeted therapy for metastatic colorectal cancer: role of aflibercept. Clin Colorectal Cancer. 2013;12(2):73-85. DOI: 10.1016/j.clcc.2012.08.001

6. Deng X, Qiu Q, Yang B, Wang X, Huang W, Qian H. Design, synthesis and biological evaluation of novel peptides with anticancer and drug resistance-reversing activities. Eur J Med Chem. 2015;89:540-8. DOI:10.1016/j.ejmech.2014.10.072

7. Luqmani Y. Mechanisms of drug resistance in cancer chemotherapy. Medical principles and practice: international journal of the Kuwait University, Health Science Centre. 2004;14:35-48. DOI:10.1159/000086183

8. Capdevila J, Saura C, Macarulla T, Casado E, Ramos F, Tabernero J. Monoclonal antibodies in the treatment of advanced colorectal cancer. EJSO. 2007;33:S24-S34. DOI: 10.1016/j. ejso.2007.09.025

9. Sapra P, Shor B. Monoclonal antibody-based therapies in cancer: advances and challenges. Pharmacol Ther. 2013;138(3):452-69. DOI:10.1016/j.pharmthera.2013.03.004

10. Zare H, Rajabibazl M, Rasooli I, Ebrahimizadeh W, Bakherad $\mathrm{H}$, Ardakani LS. Production of nanobodies against prostatespecific membrane antigen (PSMA) recognizing LnCaP cells. Int J Biol Marker. 2014;29(2 (April-June)):169-79.DOI:10.5301/ jbm.5000063

11. Cortez-Retamozo V, Backmann N, Senter PD, Wernery U, De Baetselier P, Muyldermans S, et al. Efficient cancer therapy with a nanobody-based conjugate. Cancer Res. 2004;64(8):2853-7. DOI: 10.1158/0008-5472.CAN-03-3935

12. Kim SJ, Park Y, Hong HJ. Antibody engineering for the development of therapeutic antibodies. Mol Cell. 2005;20(1):1729.

13. Weisser NE, Hall JC. Applications of single-chain variable fragment antibodies in therapeutics and diagnostics. Biotechnol Adv. 2009;27(4):502-20. DOI:10.1016/j.biotechadv.2009.04.004

14. Baghban R, Gargari SLM, Rajabibazl M, Nazarian S, Bakherad H. Camelid-derived heavy chain nanobody against Clostridium botulinum neurotoxin E in Pichia pastoris. Biotechnol Appl Biochem. 2016;63(2):200-5. DOI: 10.1002/bab.1226.

15. Ghassabeh GH, Muyldermans S, Saerens D. Nanobodies, single-domain antigen-binding fragments of camelid heavychain antibodies. Current Trends in Monoclonal Antibody Development and Manufacturing. Springer; 2010. p. 29-48. DOI: 10.1007/978-0-387-76643-0_3

16. Oliveira S, van Dongen GA, Stigter-van Walsum M, Roovers $\mathrm{RC}$, Stam JC, Mali W, et al. Rapid visualization of human tumor xenografts through optical imaging with a near-infrared fluorescent anti-epidermal growth factor receptor nanobody. Mol Imaging. 2012;11(1):33. DOI: 10.2310/7290.2011.00025.

17. Smolarek D, Bertrand O, Czerwinski M. Variable fragments of heavy chain antibodies (VHHs): a new magic bullet molecule of medicine? Postepy Hig Med Dosw (Online). 2012 Jun 14;66:348-
58. e-ISSN 1732-2693

18. Ebrahimizadeh W, Mousavi Gargari S, Rajabibazl M, Safaee Ardekani L, Zare H, Bakherad H. Isolation and characterization of protective anti-LPS nanobody against V. cholerae O1 recognizing Inaba and Ogawa serotypes. Appl Microbiol Biotechnol. 2013;97(10):4457-66. DOI; 10.1007/s00253-0124518-x

19. Yasutomi J, Koda K, Saito N, Nakajima N, Nasoff M, McKnight $\mathrm{M}$, et al. Identification of the immunoreactive peptide sequence for AgSK1, an adenocarcinoma-restricted antigen. Tissue Antigens. 2000;55(2):157-61. DOI: 10.1034/j.1399-0039.2000.550208.x

20. Koda K, Nakajima N, Saito N, Yasutomi J, McKnight M, Glassy M. A human natural antibody to adenocarcinoma that inhibits tumour cell migration. Br J Cancer. 1998;78(10):1313. DOI:10.1038/bjc.1998.67

21. Araste F, Ebrahimizadeh W, Rasooli I, Rajabibazl M, Mousavi Gargari S. A novel VHH nanobody against the active site (the CA domain) of tumor-associated, carbonic anhydrase isoform IX and its usefulness for cancer diagnosis. Biotechnol Lett. 2014;36(1):21-8. DOI: 10.1007/s10529-013-1340-1

22. Riethmüller G, Gruber R, Schneider-Gädicke E, Schlimok G, Witte J, Raab R, et al. Randomised trial of monoclonal antibody for adjuvant therapy of resected Dukes' C colorectal carcinoma. The Lancet. 1994;343(8907):1177-83. DOI:10.1016/S01406736(94)92398-1

23. Bokemeyer C, Bondarenko I, Hartmann J, De Braud F, Schuch G, Zubel A, et al. Efficacy according to biomarker status of cetuximab plus FOLFOX-4 as first-line treatment for metastatic colorectal cancer: the OPUS study. Ann Oncol. 2011;22(7):153546. DOI: 10.1093/annonc/mdq632

24. Sood A, McClain D, Maitra R, Basu-Mallick A, Seetharam R, Kaubisch A, et al. PTEN gene expression and mutations in the PIK3CA gene as predictors of clinical benefit to anti-epidermal growth factor receptor antibody therapy in patients with KRAS wild-type metastatic colorectal cancer. Clin Colorectal Cancer. 2012;11(2):143-50. DOI:10.1016/j.clcc.2011.12.001

25. Misale S, Yaeger R, Hobor S, Scala E, Janakiraman M, Liska D, et al. Emergence of KRAS mutations and acquired resistance to anti-EGFR therapy in colorectal cancer. Nature. 2012;486(7404):532-6. DOI:10.1038/nature11156

26. Bakherad H, Mousavi Gargari S, Rasooli I, RajabiBazl M, Mohammadi M, Ebrahimizadeh W, et al. In Vivo Neutralization of Botulinum Neurotoxins Serotype E with Heavy-chain Camelid Antibodies (VHH). Mol Biotechnol. 2013;55(2):15967. DOI: 10.1007/s12033-013-9669-1

27. Muyldermans S, Baral TN, Retamozzo VC, De Baetselier P, De Genst E, Kinne J, et al. Camelid immunoglobulins and nanobody technology. Vet Immunol Immunopathol. 2009;128(1-3):178-83. DOI:10.1016/j.vetimm.2008.10.299

28. Chang H, Koda K, Chang S, Baird S. AgSK1, a novel carcinoma associated antigen. Cancer Res. 1993;53(5):1122-7.

29. Williams BR, Sharon J. Polyclonal anti-colorectal cancer Fab phage display library selected in one round using density gradient centrifugation to separate antigen-bound and free phage. Immunol Lett. 2002;81(2):141-8. DOI:10.1016/S01652478(02)00004-4

30. Zhou Y, Zhang J, Jin H, Chen Z, Wu Q, Li W, et al. Prokaryotic expression and refolding of EGFR extracellular domain and generation of phage display human $\mathrm{scFv}$ against EGFR. Biomed Pharmacother. 2013;67(8):737-43. DOI:10.1016/j. biopha.2013.03.019 